\title{
Manuais do professor e atividades de produção textual em livros didáticos de português: um estudo da relação teoria-prática
}

\author{
Raquel Gomes Palmeira \\ (UEPB-Campus VI) \\ Danielly Vieira Inô Espíndula \\ (UEPB-Campus VI)
}

\begin{abstract}
Resumo
O objetivo deste trabalho é confrontar o discurso teórico construído no Manual do Professor, em dois livros didáticos de português destinados ao ensino médio, e as propostas de produção textual do gênero notícia, a fim de verificar se há correlação entre a teoria escolhida e a prática proposta.
\end{abstract}

Palavras-chave: Livro didático, manual do professor, produção textual.

\begin{abstract}
In this paper, we compare the theoretical discourse in the teacher's guide and the proposal for writing activities in two Portuguese language textbooks for high school. Focusing on the news article genre, we attempt to verify whether there is a correspondence between theory and practice in these textbooks.

Keywords: textbook, teacher's guide, writing.
\end{abstract}

\section{INTRODUÇÃO}

Este artigo é parte integrante do projeto "Manual do professor e atividades de produção textual em livros didáticos: uma relação (des) articulada”, desenvolvido através do PIBIC/CNPq/UEPB, e objetiva confrontar o discurso teórico construído em manuais do professor (também denominados em alguns didáticos de “assessoria pedagógica”) e as propostas de produção textual, especificamente do gênero notícia, de dois livros didáticos destinados ao ensino médio: Cereja \& Magalhães (2004) e Tufano \& Sarmento (2004). A definição do corpus se deu com base na aplicação de questionários a professores do ensino médio atuantes em escolas publicas e particulares do cariri paraibano, que resultou na constatação de que os referidos manuais são os mais utilizados nos municípios percorridos durante a pesquisa.

Pela limitação de espaço, apresentaremos, ao longo desta análise, apenas parte dos resultados encontrados durante o desenvolvimento do projeto. No entanto, continuamos 
seguindo os objetivos propostos: refletir sobre a articulação (ou não) entre as orientações teóricas e a abordagem presente nas atividades, e como as possíveis contradições entre esses dois polos (teoria e prática) podem influenciar o desenvolvimento do aluno enquanto leitor e produtor de textos.

\section{FUNDAMENTAÇÃO TEÓRICA}

Há muito tempo se ouve falar no livro didático (LD) como um dos principais instrumentos pedagógicos utilizados no exercício da docência. Algumas mudanças, porém, ocorridas no contexto educacional brasileiro entre as décadas de 60 e 70, influenciaram significativamente a elaboração de "novos” manuais didáticos. O acesso às escolas públicas foi democratizado: a prática de aplicação do exame de admissão, que selecionava quem teria acesso à educação, foi extinta, e as salas de aula, que até então eram frequentadas apenas pela elite, passaram a comportar também a população mais pobre. Neste mesmo período, foi também instituída a LDB 5692/71, que propaga a concepção de Língua Portuguesa como instrumento de comunicação e expressão.

Diante de tais fatos, as escolas passam a vivenciar uma realidade diferente: o novo perfil de alunos (que agora chegam a quantidades muito maiores) exige um maior número de professores. Estes, no entanto, começam a perder autonomia e prestígio profissional, recebendo baixos salários e acumulando muitas horas de trabalho diário. Logo, assim como as escolas, os LDs também necessitam adequar-se à nova realidade: As clássicas antologias cedem lugar a “(...) um novo tipo de material didático (...) apresentando não somente os conteúdos, mas também as atividades didáticas” (Bunzen e Rojo, 2005:79).

Segundo estes mesmos autores,

(...) dirigindo-se a um professor apreciado como mal formado, sem tempo para preparação e correção de atividades escolares, devido a sua grande sobrecarga de trabalho (...), o livro assume para si a tarefa de estruturar as aulas até porque, muitas vezes, ele permanece mais tempo nas escolas que os próprios professores. (p.80)

Surge, então, um novo modelo de LD, agora com a função de estruturar o trabalho pedagógico, não apenas através da exposição de conteúdos, mas também de atividades que possibilitariam uma maior facilidade na aprendizagem destes. Assim, os manuais didáticos já não são vistos apenas como material de apoio, mas como metodologia de ensino. De acordo com Batista (2004), é nesta fase que os LDs passam a se construir 
(...) como se fossem as aulas. A voz que neles se constitui, em vez de apoiar, manter e subsidiar a voz do professor, apaga-a e a substitui. Sua sequência torna-se a sequência das aulas e sua realização passa a marcar o tempo escolar. (...) é um livro, mas é também o caderno de exercícios, a voz do professor, o planejamento, a progressão das aulas. (p.58)

Assumindo, então, esta função estruturadora do trabalho em sala de aula e buscando construir uma prática de ensino mais eficaz, os livros didáticos passam a apresentar também orientações mais específicas, direcionadas ao professor usuário: são os “manuais do professor”, que apresentam, além da estrutura da obra e algumas justificativas para a sua elaboração, propostas para sua utilização e também uma exposição de conteúdos teóricos, ou seja, o LD assume a "voz" do professor, até mesmo nos momentos de realização e/ou correção de atividades.

Estas orientações configuram um "manual” do "manual didático": além de fornecerem explicações sobre a estruturação do livro do aluno, dividem-se entre abordagens teóricas e variadas sugestões de atividades que o professor pode realizar. Além disso, trazem uma característica marcante: todos os exercícios propostos ao longo da obra para os alunos estão acompanhados das respectivas respostas; ou seja: o manual dita o que ensinar e como ensinar (apresenta um passo a passo para o desenvolvimento das aulas, como as atividades devem ser aplicadas e, ainda, como devem ser corrigidas).

No tocante às propostas de produção textual presentes nesse novo livro didático, o tradicional ensino de redação ainda predominava. Nestas circunstâncias, o termo redação não poderia ser melhor utilizado, já que designava somente a prática de escrever, redigir, sempre de acordo com as regras da gramática normativa, reproduzindo um modelo da clássica tipologia narração/descrição/dissertação, como se o único objetivo das aulas de Língua Portuguesa fosse medir a competência de cada aluno no exercício dessa escrita padronizada. Também não se percebe, ainda, nenhuma referência às condições do texto, como se o professor fosse o único interlocutor possível, o que é ratificado por Bezerra (2007):

Trata-se do ensino de redação, entendida como um texto destituído de contexto, com ênfase em sua estrutura e no código linguístico, que são avaliados pelo professor (p. 134).

Contudo, a partir das décadas de 70 e 80, emergem outros fatores que, indiscutivelmente, podem ser considerados determinantes na mudança dessa perspectiva de ensino de redação para ensino de produção textual e, consequentemente, no processo contínuo de transformações pelo qual passaram os manuais didáticos. Inicialmente, há que 
se considerar a elaboração de documentos oficiais para orientar e regulamentar o ensino de Língua Portuguesa: as LDBs, os PCNs e o PNLD.

Diante desses avanços, a concepção estruturalista baseada nos trabalhos de F. de Saussure é deixada para trás, cedendo espaço, a partir do final da década de 90, às abordagens baseadas em princípios teóricos sociointeracionistas, segundo os quais a língua se constrói socialmente, através do uso que o sujeito faz dela nas situações comunicativas, ou seja, a língua é interação. Já os textos, considerados, até então, apenas como uma manifestação linguística determinada pelas regras do sistema, passam a ser vistos como unidades dotadas de sentido, que não se restringem apenas à forma escrita da língua: contemplam também sua modalidade oral, visto que passam a ser envolvidos (além dos fatores linguísticos), os fatores sociais, históricos, semânticos e pragmáticos, em sua elaboração e compreensão.

Devido a essas transformações, surgem, baseadas no pensamento bakhtiniano de língua como interação, as discussões sobre gêneros textuais, que passam a exercer forte influência no ensino de produção textual e na elaboração dos LDs. A noção de gênero começa a ser utilizada como referência à imensa gama de textos que se apresentam cotidianamente, nas mais diversas instâncias de uso da língua e “(...) contribuem para ordenar e estabilizar as atividades comunicativas do dia - a - dia” (Marcuschi, 2005:19).

Visto desse prisma, o ensino de produção textual apresenta-se a partir de uma nova abordagem, passando a ser entendido ainda como a escrita ou "redação" de um texto, porém considerando-se suas condições de produção e circulação: o autor tem algo a dizer, a um determinado interlocutor, com objetivos claros, em uma dada situação (contexto). O caráter social da linguagem e a função social do texto entram em evidência e a produção (ou “redação”) escolar já não é apenas uma atividade à qual o docente deve atribuir uma nota e considerar a tarefa como encerrada.

\section{ANÁLISE DOS DADOS}

\section{O que dizem os manuais destinados aos professores}

Apontados como instrumentos auxiliares no trabalho em sala da aula, os manuais do professor (também denominados “assessoria pedagógica”, em algumas obras) são suplementos inseridos nas obras didáticas, através dos quais os autores apresentam as abordagens teóricas que norteiam a elaboração dessas obras, bem como sua organização 
estrutural, além de sugestões de atividades a serem aplicadas durante as aulas de língua portuguesa e as respostas para as atividades propostas para o aluno. Neste item, procuramos analisar o discurso construído nestes manuais pelos autores de dois LDs direcionados ao ensino médio, quanto à abordagem de produção textual, atentando para as concepções de língua, texto e escrita, por acreditarmos que estes conceitos, indiscutivelmente, influenciam diretamente o processo de produção de textos.

\section{a) $\mathbf{L D}-1$}

Português: Linguagens, de Cereja \& Magalhães (2004), é dividido em três volumes (sendo um volume direcionado a cada série do ensino médio). O manual do professor é composto por 32 páginas, nas quais os autores fazem uma apresentação de toda a obra, trazem algumas sugestões para o trabalho em sala de aula, além de sugestões bibliográficas e respostas dos exercícios propostos ao longo do livro.

É possível percebermos, inicialmente, uma grande preocupação dos autores em citar as bases teóricas das quais se apropriam, tanto para produzirem o manual, quanto na organização do livro: os documentos oficiais que orientam o ensino atualmente (PCN, PCNEM, PCN+, LDB) e os estudos linguísticos, que estão sempre em evolução e vêm influenciando cada vez mais a prática de ensino de Língua Portuguesa, são bastante enfatizados no discurso desses autores:

(...) Se as mudanças da edição anterior procuraram atender às propostas feitas pela Lei de diretrizes e bases, pelas Diretrizes curriculares e pelos Parâmetros Curriculares Nacionais Ensino Médio (PCNEM), esta edição procura levar em conta, além dos princípios e sugestões desses documentos, as propostas dos Parâmetros Curriculares Nacionais + ensino (PCN+) e as últimas discussões sobre ensino de língua, produção de textos e de literatura travadas na esfera acadêmica. (Cereja \& Magalhães:3)

A concepção de ensino de língua é descrita da seguinte forma:

O ensino de língua, amparado por um suporte linguístico que tem bases na semântica, na linguística textual, na Pragmática e na Teoria do Discurso, apresenta novos conteúdos, indispensáveis à atual visão de língua e interação verbal (...) (Cereja \& Magalhães:3).

Cereja \& Magalhães (op. cit.) não deixam claras as razões pelas quais atribuem tanta ênfase ao trabalho orientado pelos documentos oficiais e estudos linguísticos; no entanto, tais observações revelam, aparentemente, que os autores reconhecem a relevância das pesquisas na área da linguística, que, por sua vez, influenciam a elaboração dos documentos oficiais na busca constante por um ensino de qualidade. Além disso, o livro 
didático, mais que um instrumento para o trabalho escolar, é também um produto de consumo, que só chega às salas de aula se for aprovado pelo programa de avaliação pedagógica do MEC (PNLD). Diante disso, muitos autores e editoras preocupam-se constantemente com adequar suas obras aos critérios estabelecidos por esse programa, critérios estes que estão em consonância com as diretrizes curriculares que orientam a melhoria na qualidade do ensino: PCN, PCNEM, LDB etc. E essa também é, provavelmente, uma das preocupações dos referidos autores. Resta observarmos se essa preocupação em trabalharem à luz dessas novas perspectivas, demonstrada no manual do professor, se concretiza na elaboração da obra, especificamente na abordagem da produção textual, que é “(...) centralizada nos gêneros textuais ou discursivos, sem deixar de lado alguns aspectos relacionados com a tipologia textual (...)” (Idem, 2004:6).

Neste sentido, os autores enfatizam o pensamento bakhtiniano sobre os gêneros textuais e, partindo da concepção de língua como sinônimo de interação, referem-se à imensa gama de textos que circulam no cotidiano:

Quando estamos numa situação de interação verbal, a escolha do gênero não é completamente espontânea, pois leva em conta um conjunto de coerções dadas pela própria situação de comunicação: quem fala, sobre o que fala, com quem fala, com qual finalidade. Todos esses elementos condicionam as escolhas do locutor, que, tendo ou não consciência deles, acaba por fazer uso do gênero mais adequado àquela situação. (Idem, 2004:7)

Além de M. Bakhtin, Cereja \& Magalhães citam outros teóricos cujas ideias também fundamentam as discussões sobre gêneros textuais, entre eles, Bernard Schnewly, que “compreende o gênero textual como uma ferramenta, (...), um instrumento que possibilita exercer uma ação linguística sobre a realidade.” (Idem, 2004:7). Baseados nessas discussões, os autores orientam o professor a adotar uma visão inovadora para o ensino de produção textual, que substitua a tradicional reprodução dos modelos narrativos, descritivos e dissertativos por uma perspectiva através da qual o aluno não venha apenas a exercitar técnicas de escrita, mas possa se sentir capaz de interagir socialmente por meio do uso da língua, nas mais diversas instâncias comunicativas, o que aponta para uma concepção de escrita como um processo através do qual o falante interage com a sociedade. Neste sentido, pudemos perceber, até aqui, que o discurso dos autores parece ser condizente com as teorias citadas anteriormente como base para a elaboração da obra. Esperamos, através da análise de algumas propostas de produção textual, observar se há esta "sintonia" entre o discurso teórico do manual do professor e as atividades direcionadas ao aluno. 
Antes, porém, de procedermos à referida análise, é preciso fazer algumas ressalvas com relação a alguns pontos do manual que chamam a atenção e devem ser comentados. Percebemos que as orientações para o professor são exatamente as mesmas nos manuais dos três volumes da obra, ou seja, não há adaptação das teorias apresentadas ao conteúdo de cada série à qual o livro é destinado. E, mesmo demonstrando tanta preocupação em auxiliar o professor na realização de um trabalho baseado no Interacionismo e no estudo dos gêneros textuais, Cereja \& Magalhães (2004) não fazem referência, no manual do professor, ao fato de que cada gênero tem suas características particulares, tais como linguagem adequada, público-alvo, suporte, etc. É cabível, então, questionarmos: se cada volume da obra apresenta gêneros diferentes, como o professor pode utilizar-se das mesmas orientações?

Um dos exemplos que melhor ilustram esta lacuna deixada pelos autores é o item denominado o jornal da sala de aula, que traz sugestões para a realização de atividades utilizando os gêneros jornalísticos:

O jornal pode fornecer inúmeras possibilidades de trabalho: debate (...); diferentes interpretações de um mesmo assunto; estudo das especificidades de cada gênero jornalístico; (...); análise de jornais voltados a leitores com diferentes interesses; e enfim, a produção de gêneros jornalísticos. (Idem, 2004:12)

O detalhe é que este item de sugestões é apresentado nos manuais de $1^{\circ}, 2^{\circ}$ e $3^{\circ}$ anos, quando, na realidade, apenas os volumes de $2^{\circ}$ e $3^{\circ}$ anos apresentam alguns gêneros jornalísticos. De que servem, portanto, estas orientações no volume 1? Acreditamos que seria muito mais relevante e útil para o professor receber orientações específicas, relacionadas aos gêneros presentes em cada volume. Se considerarmos, por exemplo, a possibilidade de um determinado professor lecionar apenas na $1^{\mathrm{a}}$ série, logicamente ele só receberá o volume correspondente a esta série, que não apresenta nenhum gênero jornalístico: qual a utilidade destas orientações para ele? Ou, onde estão as orientações de que ele necessita, sobre os gêneros que aquele volume traz? Tendo em vista o objetivo a que se presta um manual do professor, é extremamente relevante que, nele, sejam apresentadas mais informações sobre os conteúdos e de maneira mais aprofundada, tendo em vista o público a quem se destina: o professor. 


\section{b) LD - 02}

O segundo livro didático que compõe o nosso corpus é de autoria de Leila Lauar Sarmento e Douglas Tufano. Intitula-se Português: Literatura, gramática e produção textual e foi publicado pela editora Moderna, em 2004. Diferentemente do primeiro LD analisado, este se apresenta em um volume único para as três séries do ensino médio.

O manual do professor é composto por 56 páginas que se subdividem em apresentação da obra, comentário dos autores sobre cada capítulo e sugestões de atividades. Além disso, como já é comum, o manual traz também as respostas de todas as atividades do livro.

Tufano \& Sarmento (2004) também são muito breves em seu discurso acerca da produção textual. Não fazem referência a nenhum teórico desta área e não apresentam claramente suas concepções de língua, texto ou escrita. Apenas repetem, no decorrer de todo o discurso, que a abordagem de produção textual pauta-se também na teoria dos gêneros, o que aponta para a perspectiva de língua como interação: “ (...) apresentaremos inicialmente os três modos de organização do texto - narração, descrição, dissertação -, depois indicamos, separadamente, como são usados para construir os distintos gêneros textuais.” (p. 4). Dizem basear-se em "três elementos - exemplo, teoria e prática” (p. 4) e afirmam que sua preocupação é “(...) fornecer subsídios teóricos para que o aluno seja capaz de identificar e escolher o modo de organização do texto mais adequado a cada situação, assim como de produzir seus textos em diferentes situações de comunicação” (p. 4).

Percebemos, então, que, apesar de não fazerem nenhuma referência à concepção de língua como interação, proposta por Bakhtin, aderem a esta perspectiva, já que demonstram preocupação em trabalhar a diversidade textual (gênero), auxiliando o aluno a identificar o mais adequado para cada situação comunicativa. Ao final do comentário sobre a abordagem de produção textual, os autores apresentam seu objetivo: “Nosso objetivo é que, ao final do curso, os alunos tenham adquirido ferramentas para amadurecer e desenvolver plenamente suas habilidades relacionadas à produção de textos orais e escritos” (p. 5).

No item a seguir, procuramos completar o nosso estudo de teoria e prática nos referidos LDs (objetivo principal deste trabalho) através da análise de propostas de produção textual referentes ao gênero notícia. Assim, poderemos verificar se o discurso teórico apresentado nestes manuais está em sintonia com as atividades direcionadas aos alunos. 


\section{CONFRONTANDO A PROPOSTA TEÓRICA E A ABORDAGEM DO GÊNERO NOTÍCIA}

Observaremos, a partir de agora, as propostas de produção textual dos dois LDs mencionados acima, referentes ao gênero notícia. Iniciaremos nossa análise por Português: Linguagens (CEREJA \& MAGALHÃES, 2004), considerando que este foi o mais citado pelos professores que participaram da pesquisa. A única proposta de produção de notícia é apresentada no volume 2 da coleção, destinado aos alunos da $2^{a}$. série do Ensino Médio: em um capítulo destinado exclusivamente ao estudo deste gênero, os autores apresentam um exemplar de notícia, seguido por um exercício no qual são expostos alguns conceitos e, em seguida, questões sobre a estrutura do gênero e o conteúdo do texto que serviu de exemplo:

4. (...). Na notícia em estudo, que parágrafos constituem o texto?

6. Observe a linguagem empregada no texto

a) Que características ela apresenta?

$(\ldots)$

b) Em que variedade linguística está?

(Cereja \& Magalhães, 2004:265)

Algo que chama a atenção é o fato de que não há informações a respeito dos diferentes suportes existentes para este gênero e, no entanto, uma das questões do exercício pergunta exatamente “em que veículos são transmitidas as notícias” (p.267). Pressupõe-se que o aluno já dispõe desta informação, mas o único exemplo deste gênero apresentado no capítulo é retirado de um jornal, o que seria insuficiente para que se tenha conhecimento sobre a circulação da notícia em outros suportes. Nesse caso cabe ao professor, necessariamente, complementar essas informações e aproveitar o conhecimento que o aluno já traz sobre esse gênero do seu dia a dia.

A proposta de produção proporciona ao aluno escolher se seu texto abordará algum fato que tenha ocorrido recentemente no nosso país ou no mundo, independentemente do tema abordado (política, educação, violência etc.), ou um fato que tenha ocorrido no bairro ou na escola, também sem restrições ao tema. Em seguida, são dadas algumas orientações:

a) Faça um planejamento. Leia jornais e revistas, (...), procurando obter o maior número possível de informações. 
b) Tenha em mente o leitor do seu texto; (...). Procure responder às perguntas que um leitor faria: o quê? Quando? Onde? Como? Por quê?

c) Comece seu texto pela informação que considera mais interessante (...) para o leitor (...).

d) Faça um rascunho e só passe sua notícia a limpo depois de fazer uma revisão cuidadosa, (...). Refaça o texto quantas vezes forem necessárias.

(Cereja \& Magalhães, 2004:269).

Percebemos que, nesta proposta, os autores realmente incorporam o discurso teórico apresentado no manual do professor, adotando uma visão de língua como um processo de interatividade entre o sujeito e o meio social. Deixam claras as condições de produção e o aluno é orientado a pensar: o que dizer?; para quem?; com que objetivos? Assim, o texto já não se reduz apenas à reprodução de um modelo estrutural e passa a ser observado sob uma ótica interacionista: a concretização do uso da língua pelos sujeitos, em uma determinada situação de interação social. Além disso, há orientações sobre a prática de reescrita do texto, o que caracteriza uma concepção de escrita como processo e não um produto que se limita ao preenchimento de um espaço no caderno do aluno e é esquecido após o final da aula.

Os autores também sugerem a circulação do texto além do espaço da sala de aula:

(...) escolham um mural ou uma parede da escola para montar o jornal. Convidem colegas de outras séries, professores e funcionários, amigos e familiares para lê-lo.

(Cereja \& Magalhães, 2004:268)

A ideia de convidar outras pessoas que não fazem parte da escola pode ajudar o aluno a se conscientizar de que produzir um texto não é apenas uma tarefa escolar, mas um meio de interação entre ele e a sociedade, através da língua. Além disso, merece destaque o fato de que os textos produzidos pela turma serão organizados em um jornal produzido por eles e divulgado na comunidade escolar.

No segundo LD que compõe o nosso corpus, os autores Tufano \& Sarmento (2004) também apresentam apenas uma proposta de produção do gênero notícia. O capítulo em que está inserida aborda também outros gêneros jornalísticos; também é apresentada uma breve exposição sobre a estrutura da notícia e apenas um exemplo, retirado de um jornal. A proposta é centrada na exibição de uma foto ilustrativa, a partir da qual o aluno deve escrever sua notícia: "Escreva uma noticia a partir da foto que se segue. Lembre-se de que a notícia é formada de manchete, lide, corpo.” (p. 398).

Na elaboração da proposta, os autores enfatizam o modelo estrutural que o texto deve manter, embora já tenham explicado detalhadamente cada parte de uma notícia (manchete, 
lide, corpo) na página anterior. No entanto, na etapa que denominam avaliação, o aluno é orientado a analisar o texto de um colega, observando se esse texto responde aos questionamentos “O quê? Quando? Onde? Como? Por quê?” (p. 398), o que pode ajudá-lo a compreender a importância das condições de produção específicas desse gênero, embora os autores não utilizem esta expressão. Além disso, há também uma sugestão de reescrita do texto, ainda que não seja explicada para o aluno a importância desta etapa no processo de produção textual. Quanto à circulação do texto, não encontramos nenhum comentário ou sugestão dos autores - exceto a proposta de trocá-lo com um colega de classe, para que um avalie o texto do outro -, o que aponta para uma perspectiva de produção textual baseada exclusivamente na estrutura do texto e não no seu funcionamento na sociedade, como sugere uma concepção de língua interacionista e as teorias sobre gêneros textuais.

\section{CONSIDERAÇÕES FINAIS}

A partir da análise dos exemplos acima, pudemos perceber que a perspectiva realmente adotada na elaboração das propostas de produção textual ainda se distancia bastante do discurso teórico dos autores, exposto nos manuais destinados ao professor. Dos dois LDs citados aqui, apenas Cereja \& Magalhães (2004) conseguem articular de forma mais consistente a teoria citada no manual à proposta apresentada. Tufano \& Sarmento (2004) limitam-se ao próprio discurso, já que não citam nenhuma teoria que tenha servido de base na elaboração da obra; no entanto, a repetição constante da afirmação de que trabalhariam com os gêneros textuais aponta para uma visão de língua como interação e que esta se concretiza através do uso real, feito pelos falantes, o que resulta na imensa diversidade de gêneros (orais ou escritos) que circulam diariamente.

Ficou claro que, no discurso teórico dos manuais observados, os autores insistem em afirmar que a abordagem das suas obras filia-se ao interacionismo sócio-discursivo. No entanto, isso só se confirma em alguns aspectos; outros (como a falta de referência às condições de produção de cada texto) ainda deixam a desejar e continuam aproximando-se apenas da visão de texto como uma redação, ou seja, uma tarefa escolar que objetiva apenas fazer cada aluno treinar as técnicas da escrita-padrão.

Quanto à visível preocupação dos autores em afirmarem que suas obras estão de acordo com as orientações dos PCNs, é possível que esteja relacionada ao fato de que o LD é também um produto de consumo do mercado editorial e, para ser bem visto pelos avaliadores do MEC e comprado em grandes quantidades pelo governo, é necessário que 
esteja adaptado às teorias que influenciam a elaboração desses documentos oficiais. É tarefa, então, do professor que utiliza esses livros desenvolver estratégias capazes de suprir essas lacunas e transformar a prática de produção textual em algo interessante para o aluno, evitando que continue, com o passar do tempo, limitada apenas a exaustivos exercícios de escrita.

\section{REFERÊNCIAS}

Batista, A. A. G. (2004). Um livro didático “moderno”. In: Batista. A. A. G. O texto

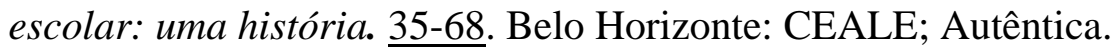

Bezerra, M. A. (2007). O livro didático de português: uma breve retrospectiva. In: Espíndola, L. \& Souza, M.E.V. (orgs.). O texto: vários olhares, múltiplos sentidos. 133158. João Pessoa: Editora Universitária/UFPB.

Bunzen, C. \& Rojo, R. (2005). Livro didático de língua portuguesa como gênero do discurso: autoria e estilo. In: Costa Val, M.G \& Marcuschi, B.(Orgs.). Livro didático de língua portuguesa: letramento e cidadania. 73-113. Belo Horizonte: CEALE; Autêntica.

Marcuschi, L. A. (2005). Gêneros textuais: Definição e Funcionalidade. In: Dionisio, A.P. et al. Gêneros textuais e ensino. Rio de Janeiro: Lucerna.

Schnewly, B. \& Dolz, J. (2004). Gêneros orais e escritos na escola. São Paulo: Mercado de Letras.

\section{AS AUTORAS}

Raquel Gomes Palmeira é aluna do curso de Licenciatura Plena em Letras/Português, da Universidade Estadual da Paraíba (Campus VI) e foi bolsista de iniciação científica do PIBIC/CNPq/UEPB, cota 2009/2010, desenvolvendo o projeto Manual do professor $e$ atividades de produção textual em livros didáticos: uma relação (des)articulada , sob orientação da Profa. Danielly Vieira Inô Espíndula.

E-mail: quelsume@hotmail.com

Danielly Vieira Inô Espíndula é graduada em Licenciatura Plena em Letras pela Universidade Federal de Campina Grande (2002) e Mestre em Letras pela Universidade Federal da Paraíba (2006). Entre os anos de 2002 e 2007 foi professora de produção textual da Escola Virgem de Lourdes, atuando nos níveis Fundamental e Médio e desde 2007 é professora efetiva de Linguística na Universidade Estadual da Paraíba (Campus VI), onde atua desenvolvendo pesquisas na área de produção textual e leitura.

E-mail: dany-vi@yahoo.com.br 